\title{
El Niño and health risks from landscape fire emissions in southeast Asia
}

\author{
Miriam E. Marlier ${ }^{1 \star}$, Ruth S. DeFries ${ }^{2}$, Apostolos Voulgarakis ${ }^{3 \dagger}$, Patrick L. Kinney ${ }^{4}$, \\ James T. Randerson ${ }^{5}$, Drew T. Shindell ${ }^{3}$, Yang Chen $^{5}$ and Greg Faluvegi ${ }^{3}$
}

Emissions from landscape fires affect both climate and air quality'. Here, we combine satellite-derived fire estimates and atmospheric modelling to quantify health effects from fire emissions in southeast Asia from 1997 to 2006. This region has large interannual variability in fire activity owing to coupling between EI Niño-induced droughts and anthropogenic land-use change $e^{2,3}$. We show that during strong El Niño years, fires contribute up to $200 \mu \mathrm{g} \mathrm{m}^{-3}$ and $50 \mathrm{ppb}$ in annual average fine particulate matter $\left(\mathbf{P M}_{2.5}\right)$ and ozone surface concentrations near fire sources, respectively. This corresponds to a fire contribution of $\mathbf{2 0 0}$ additional days per year that exceed the World Health Organization $50 \mathrm{\mu g} \mathrm{m}^{-3}$ 24-hr $\mathrm{PM}_{2.5}$ interim target ${ }^{4}$ and an estimated $10,800(6,800-14,300)$-person $(\sim 2 \%)$ annual increase in regional adult cardiovascular mortality. Our results indicate that reducing regional deforestation and degradation fires would improve public health along with widely established benefits from reducing carbon emissions, preserving biodiversity and maintaining ecosystem services.

Fires are pervasive instruments of land management in the tropics for clearing debris in the process of deforestation and agricultural management. These fires enable an economical and effective method for expanding and maintaining agricultural production, but release gases (including $\mathrm{O}_{3}$ precursors) and aerosols (mostly black and organic carbon) that interact with the climate system ${ }^{5}$, degrade surface air quality ${ }^{1}$ and jeopardize public health ${ }^{6}$. Fires associated with deforestation emitted $\sim 1.0 \mathrm{Pg} \mathrm{Cyr}^{-1}$ from 2000 to 2010 (ref. 7), with considerable interannual variability from droughts in tropical forests ${ }^{8}$. Fires also contribute to $\mathrm{PM}_{2.5}$ and $\mathrm{O}_{3}$ increases, which are both detrimental to public health ${ }^{1,4}$. Projections of greater fire activity in a warming climate ${ }^{9}$ suggest increasing contributions to atmospheric concentrations and population exposure.

Globally, most fires occur in Africa and South America ${ }^{8}$, but recent studies have highlighted the importance of southeast Asia because of high population densities near high fire activity ${ }^{10}$. Regional emissions may differ by a factor of 50 between opposite phases of the El Niño-Southern Oscillation. In the Global Fire Emissions Database version 3 (GFED3), regional fire emissions were 1,069 $\mathrm{Tg} \mathrm{C}$ during the $1997 \mathrm{El}$ Niño but only $21 \mathrm{Tg} \mathrm{C}$ during the $2000 \mathrm{La} \mathrm{Niña}^{8}$, illustrating the nonlinearity between fires and drought ${ }^{11}$. During the warm phase of El Niño-Southern Oscillation and the Indian Ocean Dipole, cool sea surface temperature anomalies near Indonesia decrease regional rainfall ${ }^{2,12}$. Landowners ignite fires to clear land and manage agricultural $\operatorname{areas}^{3}$ and, although typically too wet to combust, deforestation
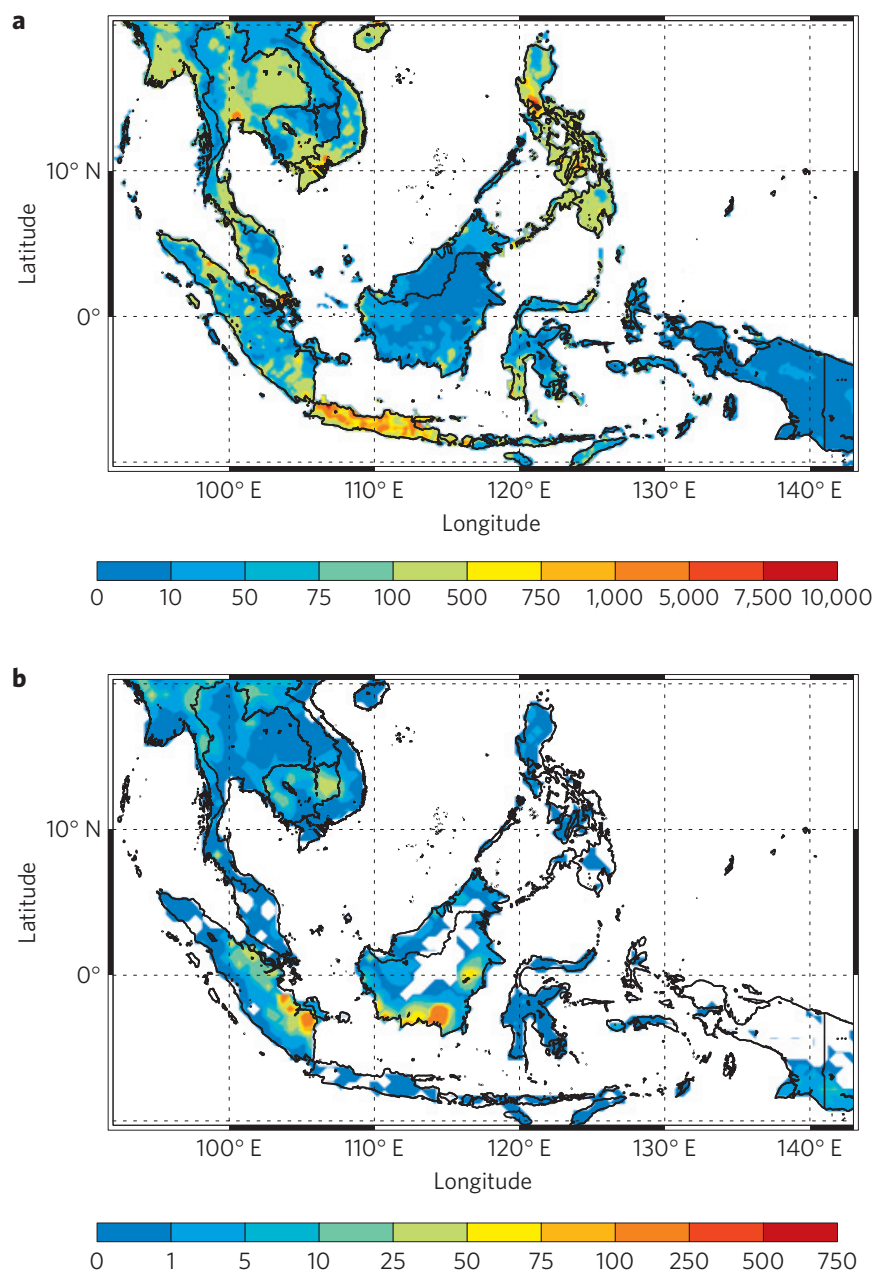

Figure 1 | Study area population and locations of fire activity. a, 2005 population density, in persons per $\mathrm{km}^{2}$, for countries belonging to the ASEAN. Data from CIESIN GPWv3 (ref. 29) at $0.25^{\circ}$ resolution. b, 1997-2006 mean fire emissions, in $\mathrm{g} \mathrm{C}^{2}$ per month at $0.5^{\circ}$ resolution, from the GFED3 (ref. 8).

and degradation have enhanced the susceptibility of peatland forests (with carbon-rich peat deposits) to human-ignited fire during droughts ${ }^{13}$.

\footnotetext{
${ }^{1}$ Department of Earth and Environmental Sciences, Lamont-Doherty Earth Observatory of Columbia University, Palisades, New York 10964, USA, ${ }^{2}$ Department of Ecology, Evolution, and Environmental Biology, Columbia University, New York, New York 10027, USA, ${ }^{3}$ NASA Goddard Institute for Space Studies and Columbia University, New York, New York 10025, USA, ${ }^{4}$ Mailman School of Public Health, Columbia University, New York, New York 10032, USA, ${ }^{5}$ Department of Earth System Science, University of California, Irvine, California, 92697, USA. †Present address: Department of Physics, Imperial College London, London, SW7 2AZ, UK. *e-mail: marlier@ldeo.columbia.edu.
} 

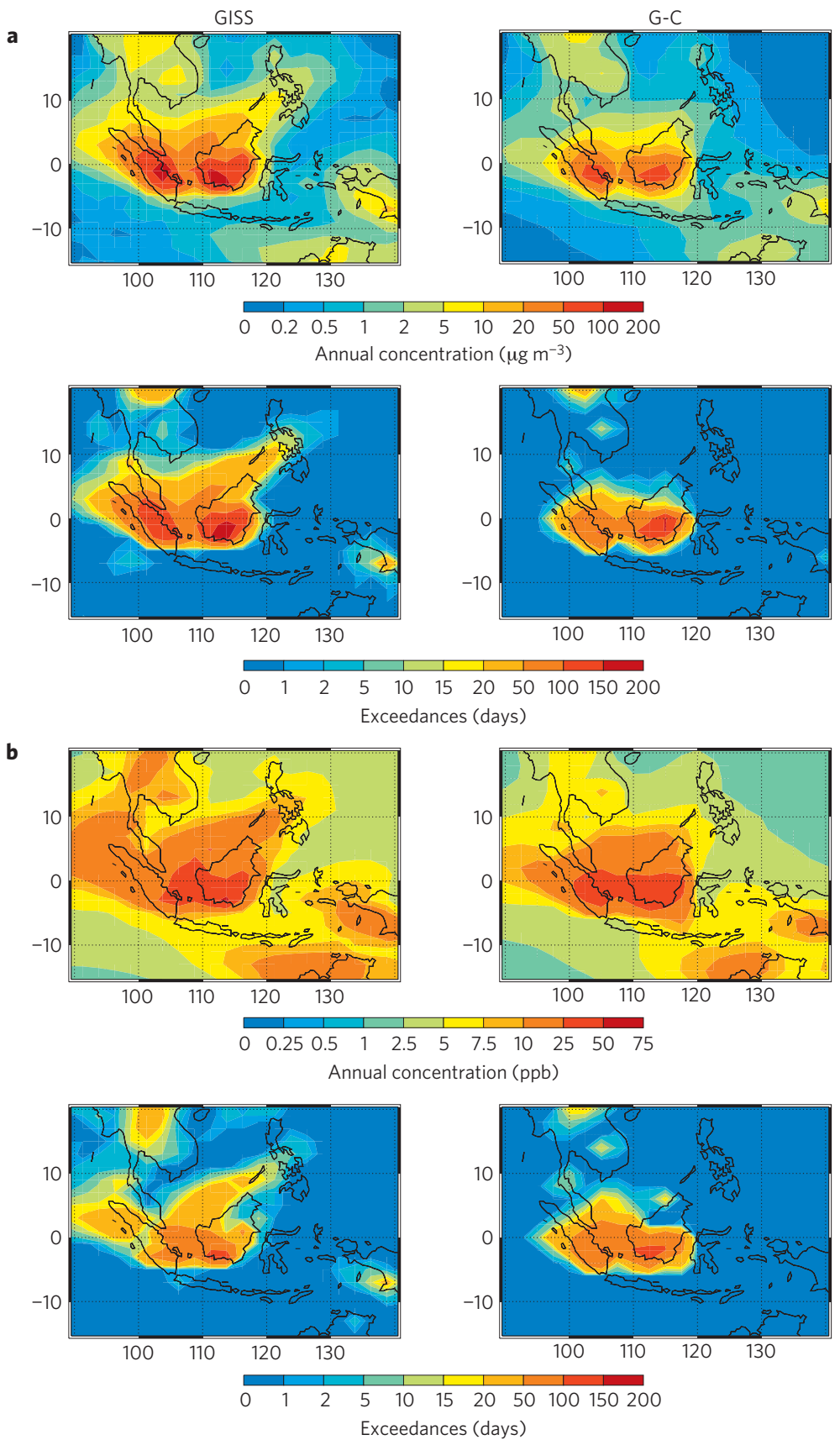

Figure 2 | Modelled annual mean surface concentrations and corresponding additional daily exceedances in 1997 owing to fires only. a,b, PM 2.5 (a) and $\mathrm{O}_{3}$ (b). Annual concentrations (in $\mu \mathrm{m}^{-3} \mathrm{PM}_{2.5}$ and $\mathrm{ppb} \mathrm{O}_{3}$, respectively) and daily exceedances over WHO interim targets $\left(50 \mu \mathrm{m}^{-3}\right.$ daily PM 2.5 (IT-2) and $80 \mathrm{ppb} 8$-hr maximum $\mathrm{O} 3$ (IT-1)). Annual concentrations are from 24-hr $\mathrm{PM}_{2.5}$ and 8-hr maximum $\mathrm{O}_{3}$. GISS refers to GISS-E2-PUCCINI and G-C refers to GEOS-Chem.

$\mathrm{PM}_{2.5}$ and $\mathrm{O}_{3}$ exposure increases hospital admissions and mortality from respiratory and cardiovascular diseases, even at low concentrations ${ }^{4}$. During the 1997-1998 fires in southeast Asia, daily ground-level particulate-matter concentrations reached hazardous levels ${ }^{6}$, with concomitant negative impacts on respiratory and general health ${ }^{14}$. Increases in respiratory illnesses were also reported in Singapore from transported emissions ${ }^{15}$. Although these studies offer some information on the health effects of fires, they have been confined to specific locations or time periods by limited data availability.

We expand on these local studies by using satellite data and two atmospheric models, the National Aeronautics and Space Administration (NASA) GISS-E2-PUCCINI general circulation model and
Harvard University's GEOS-Chem chemical transport model, to estimate pollutant concentrations and corresponding regional mortality from 1997 to 2006, applying existing concentration-response functions from the epidemiological literature (see Methods). Atmospheric models simulate the transport of fire emissions and formation of pollutants, offer a continuous spatiotemporal data set in a region with limited ground monitoring but large rural populations and allow us to examine how climate and emissions influence aerosol and trace-gas concentrations interannually.

Our study region is a $50^{\circ} \times 30^{\circ}$ area $\left(92.5^{\circ} \mathrm{E}-142.5^{\circ} \mathrm{E}\right.$, $20^{\circ} \mathrm{N}-10^{\circ} \mathrm{S}$ ) encompassing the Association of Southeast Asian Nations (ASEAN). In 2005, the population was approximately 540 million (Fig. 1a). Fire activity, predominately in the Indonesian 
a

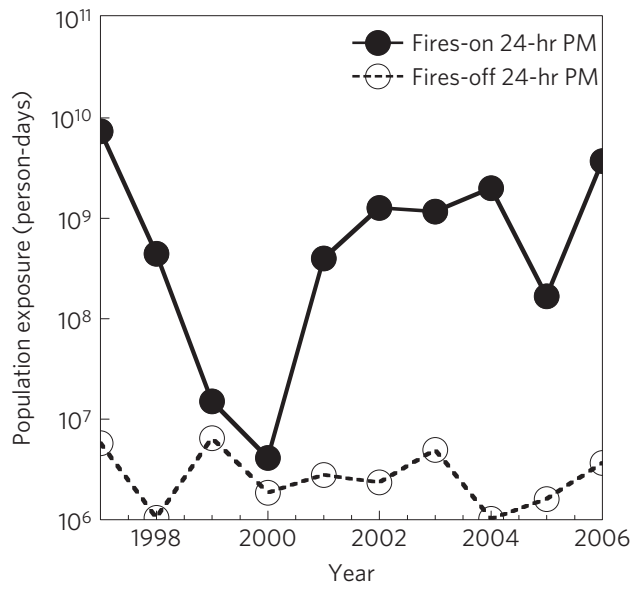

.

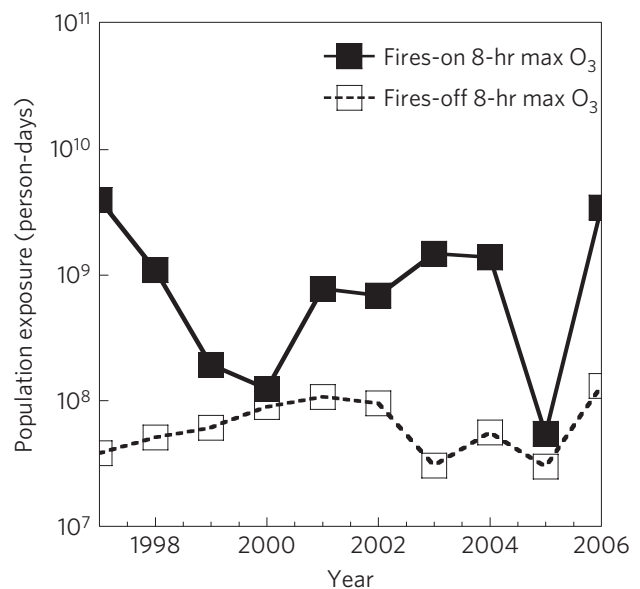

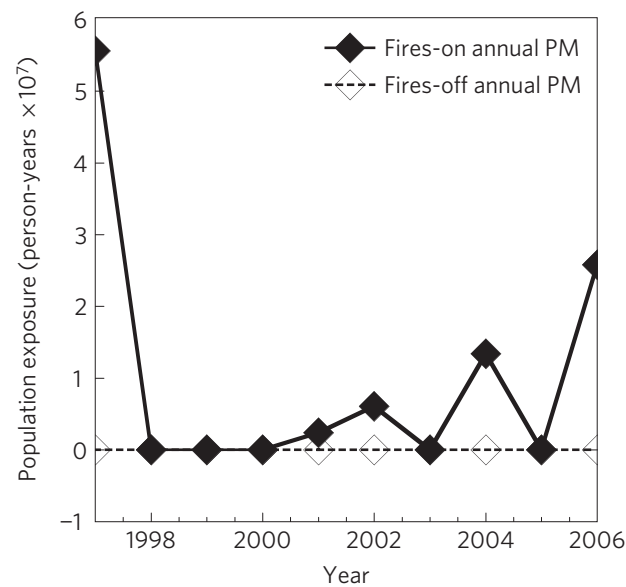

d

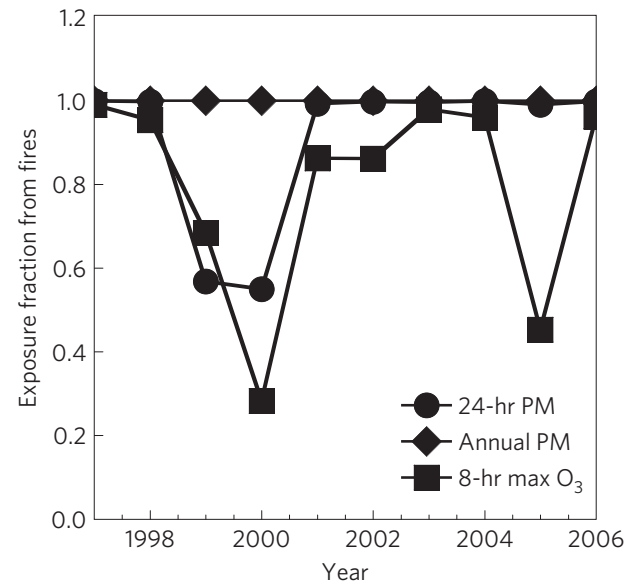

Figure 3 | Population exposure above WHO interim targets. a, Exposure over $50 \mu \mathrm{g} \mathrm{m}^{-3}$ 24-hr $\mathrm{PM}_{2.5}$ interim target (IT-2). b, Exposure over $25 \mu \mathrm{g} \mathrm{m}{ }^{-3}$ annual $\mathrm{PM}_{2.5}$ interim target (IT-2). c, Exposure over $80 \mathrm{ppb}$ 8-hr maximum $\mathrm{O}_{3}$ interim target (IT-1). d, Fraction of population exposure above each WHO interim target that is attributable to fires. Each case is calculated with and without GFED3 fire emissions using GISS-E2-PUCCINI results, which was close to the average concentration estimate. Refer to Supplementary Table S1 for estimated health effects. PM, particulate matter. Note the logarithmic scale for a and $\mathbf{c}$.

islands of Sumatra and Borneo (Fig. 1b), peaks during the dry southern monsoon of September and October, along with potential spring burning ${ }^{2,6}$.

The additional contribution of fires to annual surface $\mathrm{PM}_{2.5}$ and $\mathrm{O}_{3}$ concentrations in 1997, a strong El Niño year, greatly increases the number of days that exceeded the World Health Organization (WHO) interim targets of $50 \mu \mathrm{g} \mathrm{m}^{-3}$ 24-hr $\mathrm{PM}_{2.5}$ (IT-2) and $80 \mathrm{ppb} 8$-hr maximum $\mathrm{O}_{3}$ (IT-1), which are both twice the WHO's air-quality guidelines (Fig. 2 and Supplementary Table S1). In 1997, both models show two distinct areas of fire-derived $\mathrm{PM}_{2.5}$ over Sumatra and Borneo with concentrations increased by $50-200 \mu \mathrm{g} \mathrm{m}^{-3}$ and with increases of 50-150 days over the WHO interim targets. $\mathrm{O}_{3}$, in contrast, had widely distributed increases of $25-50 \mathrm{ppb}$ and up to 150 exceedance days. Corresponding results with all sources in 1997 are in Supplementary Fig. S1, this simulation captured the general temporal evolution seen in ground observations (Supplementary Figs. S2-S4 and Table S2).

We explored how modelled concentrations with and without fire emissions affect population exposure to WHO interim targets (Supplementary Table S1) ${ }^{4}$. Decadal exposure over these interim targets, along with the fraction of exposure owing to fire, shows how the major influence of fires was not confined to the 1997-1998 El Niño (Fig. 3). Interannual variability in exposure for both shortand long-term guidelines is dominated by the fire contribution of $\mathrm{PM}_{2.5}$ and $\mathrm{O}_{3}$; the WHO's $25 \mu \mathrm{g} \mathrm{m}^{-3}$ annual $\mathrm{PM}_{2.5}$ interim target (IT-2) is never exceeded without including fire emissions.
We also tested the sensitivity of regional health impacts, including exceedances and cardiovascular disease mortality, to using the original model or satellite-scaled model $\mathrm{PM}_{2.5}$ estimates (Supplementary Fig. S5). The mortality estimates combine modelled pollutant-concentration changes from fires with published epidemiological relationships between exposure to $\mathrm{O}_{3}$ or $\mathrm{PM}_{2.5}$ total mass and cause-specific mortality (see Methods). In Table 1, 1997 and 2000 highlight the considerable differences in health effects between years with high and low fire contributions. For example, $\mathrm{PM}_{2.5}$ annual exposure in 2000 hardly exceeds the WHO interim target and $\mathrm{O}_{3}$ exposure is 100 times lower than in 1997. During high fire years, fire emissions increase the adult cardiovascular disease mortality burden by approximately $10,800(6,800-14,300)$ annual deaths from $\mathrm{PM}_{2.5}$ exposure and an additional 4,100 $(2,300-5,900)$ annual deaths from $\mathrm{O}_{3}$.

Modelled annual adult cardiovascular disease mortality shows a strong correlation with the multivariate El Niño-Southern Oscillation index ${ }^{16}$, which was averaged over the July-October dry season (Fig. 4). We present the most conservative mortality estimates, but this relationship holds with varying relative risk relationships or durations of exposure (Supplementary Fig. S6). Reduced convection during El Niño years probably increases exposure by increasing emissions ${ }^{5,11}$ and increasing aerosol lifetimes by reducing wet deposition.

Uncertainties in our health-effect estimates come primarily from: the fire emissions data set, atmospheric modelling and 
Table 1 | Fires-only concentration, exposure and mortality using different models for an El Niño (1997) and La Niña (2000).

\begin{tabular}{|c|c|c|c|c|c|c|}
\hline \multicolumn{7}{|l|}{$\mathrm{PM}_{2.5}$} \\
\hline & \multicolumn{2}{|c|}{$\begin{array}{l}\text { Concentration } \\
\left(\mu \mathrm{g} \mathrm{m}^{-3}\right)\end{array}$} & \multicolumn{2}{|c|}{$\begin{array}{l}\text { Exposure above IT-2 } \\
\left(\times 10^{6} \text { person-years) }\right.\end{array}$} & \multicolumn{2}{|l|}{$\begin{array}{l}\text { Mortality } \\
\text { ( } \times 10^{3} \text { people) }\end{array}$} \\
\hline & 1997 & 2000 & 1997 & 2000 & 1997 & 2000 \\
\hline GISS & 7.8 & 0.3 & 55.6 & 0.0 & $9.9(8.0-11.4)$ & $1.0(0.8-1.2)$ \\
\hline $\mathrm{G}-\mathrm{C}$ & 3.7 & 0.2 & 25.8 & 0.0 & $8.7(6.8-10.7)$ & $1.5(1.1-1.9)$ \\
\hline GISS MISR & 10.7 & 0.4 & 57.0 & 0.0 & $11.2(9.6-13.5)$ & $1.3(1.0-1.6)$ \\
\hline G-C MISR & 7.4 & 0.5 & 59.1 & 4.7 & $10.1(8.1-11.8)$ & $1.7(1.4-2.1)$ \\
\hline GISS MODIS & 12.0 & 0.4 & 66.6 & 0.0 & $12.5(10.1-14.2)$ & $1.5(1.1-1.8)$ \\
\hline G-C MODIS & 8.3 & 0.5 & 50.3 & 0.0 & $12.1(9.7-14.3)$ & $2.3(1.8-2.8)$ \\
\hline Average & 8.3 & 0.4 & 52.4 & 0.8 & $10.8(6.8-14.3)^{\star}$ & $1.6(0.8-2.8)^{\star}$ \\
\hline \multicolumn{7}{|l|}{$\mathrm{O}_{3}$} \\
\hline & \multicolumn{2}{|c|}{$\begin{array}{l}\text { Concentration } \\
\text { (ppb) }\end{array}$} & \multicolumn{2}{|c|}{$\begin{array}{l}\text { Exposure above IT-1 } \\
\left(\times 10^{7} \text { person-days }\right)\end{array}$} & $\begin{array}{l}\text { Mortality } \\
\left(\times 10^{3} \text { people }\right)\end{array}$ & \\
\hline & 1997 & 2000 & 1997 & 2000 & 1997 & 2000 \\
\hline GISS & 9.0 & 1.4 & 395 & 3.5 & $4.3(2.6-5.9)$ & $1.0(0.6-1.4)$ \\
\hline $\mathrm{G}-\mathrm{C}$ & 7.1 & 1.3 & 346 & 0.0 & $3.8(2.3-5.2)$ & $1.0(0.6-1.4)$ \\
\hline Average & 8.0 & 1.4 & 371 & 1.8 & $4.1(2.3-5.9)^{\star}$ & $1.0(0.6-1.4)^{\star}$ \\
\hline
\end{tabular}

Average ASEAN annual concentration owing to fires only (from 24-hr $\mathrm{PM}_{2.5}$ and 8-hr maximum $\mathrm{O}_{3}$ ); additional exposure owing to fires above the annual $25 \mu \mathrm{mg} \mathrm{m}^{-3} \mathrm{PM} 2.5$ interim target $\left(\mathrm{IT}-2 ; \times 10^{6}\right.$ person-years) and above the $80 \mathrm{ppb} 8$-hr maximum $\mathrm{O}_{3}$ interim target (IT-1; $\times 10^{7}$ person-days); cardiovascular mortality owing to fires only ( $\times 10^{3}$ people), with the range from $95 \%$ confidence intervals from epidemiological studies. GISS refers to GISS-E2-PUCCINI and G-C refers to GEOS-Chem, also with satellite scaling factors. ${ }^{\star}$ Maximum error range.

concentration-response equations. First, a previous study ${ }^{8}$ estimated fire carbon emissions uncertainty at $20 \%$ globally, though higher in equatorial Asia owing to peat carbon stock uncertainties and in years before Moderate Resolution Imaging Spectoradiometer (MODIS) data ${ }^{8}$. Second, although the lack of ground stations precludes an in-depth evaluation, available ground data and satellite aerosol optical depth (AOD) indicate that both models are probably conservative (Supplementary Fig. S3-S5). The range between the two model scenarios $\left(\mathrm{PM}_{2.5}\right.$ and $\left.\mathrm{O}_{3}\right)$ and two satellite AOD optimized results $\left(\mathrm{PM}_{2.5}\right.$ only) provides some insight about uncertainty related to transport and deposition processes. There is up to a factor of two difference between models (less among satellite-optimized estimates), but this range is expected given previous findings that model physics and parameterizations drive more variation in aerosols than emissions ${ }^{17}$. Differences in our $\mathrm{PM}_{2.5}$ concentrations are primarily driven by lower precipitation and wet deposition in the GISS model, which increase aerosol lifetime relative to GEOS-Chem (data not shown). However, for the purposes of health impacts the results are much closer (Table 1). This is owing to the nonlinear relationship between the relative risk and exposure, which reduces differences between mortality estimates at high concentrations. Finally, we address mortality equation uncertainties through $95 \%$ confidence intervals around the concentration-response estimates (Table 1) and various estimates of the relative risk and $\mathrm{PM}_{2.5}$-exposure relationship (Supplementary Tables S3 and S4 and Fig. S6). Additional epidemiological factors that we did not address are extrapolation of relative risk equations to high concentrations and applying equations developed in the USA to non-US populations. Furthermore, evidence for potential differences in $\mathrm{PM}_{2.5}$ toxicity between urban pollution in US cities and southeast Asian fire emissions is too limited to warrant using separate epidemiological equations ${ }^{18}$, so we assume that total $\mathrm{PM}_{2.5}$ mass is the most appropriate metric.

These uncertainties and additional factors contribute to our substantially lower regional $\mathrm{PM}_{2.5}$ mortality estimates relative to the global analysis of a previous study ${ }^{10}$. The two estimates are not

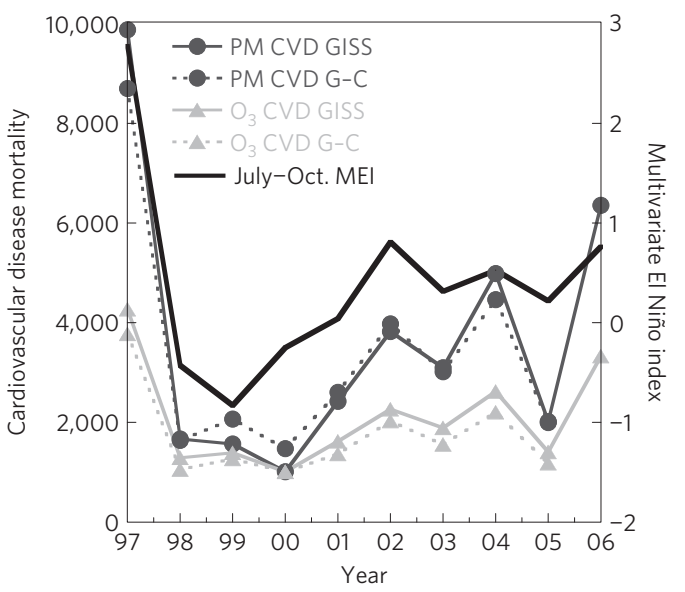

Figure 4 | Estimated additional annual cardiovascular disease mortality from exposure to fire-contributed annual $\mathrm{PM}_{2.5}$ and 24-hr $\mathrm{O}_{3}$, along with the multivariate El Niño index ${ }^{16}$. Results for 1997-2006 are from the baseline GISS-E2-PUCCINI and GEOS-Chem concentrations, with the power-law relative risk relationship for cardiovascular disease mortality. $R^{2}=0.87-0.91$ for $\mathrm{PM}_{2.5}$ and $R^{2}=0.82-0.89$ for $\mathrm{O}_{3}$. AOD-scaled results and sensitivity analysis are in Table 1, Supplementary Table S4 and Fig. S6. CVD, cardiovascular disease; MEI, multivariate El Niño-Southern Oscillation index.

directly comparable. Our conservative estimates (Supplementary Table S5) are based on a tailored regional analysis for ASEAN countries and use updated fire emissions, two atmospheric models, epidemiological equations developed over a wide concentration range and cause-specific disease estimates (Supplementary Table S6). We did not include children as the epidemiological equations were developed for adults over 30 years; this cuts out more than half of the population and ignores risks to infants and children.

Although previous work in Borneo has emphasized the value of avoided deforestation in terms of carbon emissions ${ }^{19}$, it is also 
important to account for health. By demonstrating the direct link between climate variability and health impacts from fire emissions throughout southeast Asia, we offer additional support for policies that use regional climate forecasts to restrict burning during highfire-risk seasons. Fire emissions during 1997 to 2006 repeatedly exposed $1-11 \%$ of the population in southeast Asia to $\mathrm{PM}_{2.5}$ and $\mathrm{O}_{3}$ above WHO interim targets during El Niño years. Although the regional influence of climate change is uncertain ${ }^{20}$, these observed trends would be exacerbated by the potential for more frequent droughts related to El Niño and increased baseline cardiovascular disease caused by demographic shifts towards sedentary lifestyles and increased animal-product consumption. Reducing fires from deforestation and land management would benefit public health in addition to global scale benefits for carbon storage and biodiversity.

\section{Methods}

Fire-emissions estimates are from GFED3, a global gridded monthly emissions data set that combines surface reflectance and active fire-detection data from several satellites to detect the spatiotemporal variability of burned area ${ }^{21}$. This drives a biogeochemical model that estimates fuel loads, combustion completeness and emissions $^{8}$. GFED3 is available since 1997 at $0.5^{\circ} \times 0.5^{\circ}$ resolution. We define landscape fires to include all burning sources; in southeast Asia this includes peat, forest, agricultural waste burning, deforestation and degradation.

We use two models: the NASA GISS-E2-PUCCINI general circulation model from 1997 to 2007 and Harvard University's GEOS-Chem chemical transport model $^{22}$ from 1997 to 2006. See Supplementary Information for descriptions of the models, spin-up and boundary conditions. Both were run at $2^{\circ} \times 2.5^{\circ}$ resolution, including a control run without fire emissions and a perturbed run with GFED3 emissions. We define years from 1 July to 30 June to avoid splitting a burning season into two years. As meteorological fields for GEOS-Chem are available to December 2006, we only have a complete 2006 fire year from GISS. For $\mathrm{PM}_{2.5}$, we analysed 24-hr and annual average concentrations. For $\mathrm{O}_{3}$, we used 13:00-14:00 concentrations as a proxy for the 8-hr maximum (Supplementary Fig. S4) and 24-hr concentrations for mortality calculations.

AOD data from the Multi-angle Imaging Spectroradiometer (MISR) and MODIS satellite instruments, available from 2001 to 2006, were used to scale modelled AOD; these scaling factors were then applied to modelled $\mathrm{PM}_{2.5}$ (Supplementary Fig. S5). Although AOD represents total column aerosol loading, it is often closely related to surface abundance ${ }^{23}$ and hence provides some measure of large-scale biases in the models. Scaling factors were applied to surface $\mathrm{PM}_{2.5}$ for all grid boxes, maintaining the modelled spatial and temporal distribution of aerosols.

We evaluate health effects by estimating: exposure above WHO short-term and annual air quality targets, and cause-specific adult mortality. Mortality attributable to fires combines the relative risk from changes in pollutant exposure with baseline observed mortality rates. We focus on cardiovascular disease because it is a proximal outcome from exposure that will be experienced annually. However, this underestimates total mortality owing to other long-term effects and short-term exposure. The equations that we use were developed for adults (less than half of the regional population ${ }^{24}$ ).

We applied a power-law relationship between relative risk (RR) and $\mathrm{PM}_{2.5}$. Owing to the lack of data on differential health effects of biomass smoke particles ${ }^{18}$, we use an equation developed for total $\mathrm{PM}_{2.5}$ mass:

$$
\text { Cardiovascular } \mathrm{RR}=1+\alpha(\mathrm{I} \times \mathrm{C})^{\beta}
$$

which describes the relationship between $\mathrm{PM}_{2.5}$ exposure and cardiovascular disease mortality risk over a large concentration range $e^{25}$. A previous study ${ }^{25}$ published values for $\alpha$ and $\beta$ by reanalysing previous estimates of RR and dose of $\mathrm{PM}_{2.5}$ (in $\mathrm{mg}$ ) from ambient air pollution, second-hand smoke and cigarette smoke. For cardiovascular disease, $\alpha=0.2685$ and $\beta=0.2730$. Although ambient $\mathrm{PM}_{2.5}$ concentrations from fires will not reach the cigarette smoke doses included in ref. 25 , this equation was essential owing to our high ambient concentrations above the range of other studies. As 95\% confidence intervals were given for each individual study but not the overall relationship, we refit a power-law relationship to approximate the uncertainty based on the individual studies' upper or lower limits, respectively. The annual average of 24-hr total mass $\mathrm{PM}_{2.5}$ concentrations were used for (C), assuming a constant average inhalation rate (I) of $18 \mathrm{~m}^{3} \mathrm{~d}^{-1}$ to convert to $\mathrm{PM}_{2.5}$ dose (in $\mathrm{mg}$; ref. 25). We separately calculated the RR using concentrations with and without fires owing to the equation's nonlinearity. We then followed the approach of ref. 26 to calculate the attributable fraction $(\mathrm{AF})$ and annual mortality $\left(\Delta \mathrm{M}_{\text {annual }}\right)$ :

$$
\begin{gathered}
\mathrm{AF}=(\mathrm{RR}-1) / \mathrm{RR} \\
\Delta \mathrm{M}_{\text {annual }}=\mathrm{M}_{\mathrm{b}} \times \mathrm{P} \times\left(\mathrm{AF}_{\text {fire }}-\mathrm{AF}_{\text {nofire }}\right)
\end{gathered}
$$

where equation (3) combines the results for equations (1) and (2), along with the average annual baseline mortality rate $\left(\mathrm{M}_{\mathrm{b}}\right)$, which was calculated from adult deaths owing to cardiovascular disease, averaged over the countries in ASEAN (ref. 27). Population (P) with ages greater than 30 years was from the United Nations Population Division ${ }^{24}$ and CIESIN's Gridded Population of the World version 3 and Future Estimates, aggregated to the model resolution ${ }^{28,29}$; both were interpolated from five-yearly data to annual estimates.

For $\mathrm{O}_{3}$, the linear $\mathrm{RR}$ is given by:

$$
\text { Cardiovascular } \mathrm{RR}=\exp \left[\delta\left(\mathrm{C}_{\text {fire }}-\mathrm{C}_{\text {nofire }}\right)\right]
$$

where $\delta=1.11(0.68-1.53)$ is the per cent increase in cardiovascular disease morality per $10 \mathrm{ppb}$ increase in $24-\mathrm{hr}_{3}$ concentrations, based on a meta-analysis of US and non-US studies ${ }^{30}$. Daily mortality owing to fire pollution is then estimated with equation (5):

$$
\Delta \mathrm{M}_{\text {daily }}=\left(\mathrm{M}_{\mathrm{b}} / 365\right) \times \mathrm{P} \times\left(\mathrm{AF}_{\text {fire }}-\mathrm{AF}_{\text {nofire }}\right)
$$

using equations (4) and (2), along with the population characteristics described above. We assume that mortality is evenly spread throughout the year $\left(\mathrm{M}_{b}\right.$ is not year-specific so we divide consistently by 365 ) and sum by days per year to obtain annual estimates. GEOS-Chem includes leap years, but GISS uses a fixed 365-day calendar. A previous study ${ }^{30}$ concluded that the $\mathrm{O}_{3}$ mortality burden was insensitive to particulate matter ${ }^{30}$, indicating that this is separate from $\mathrm{PM}_{2.5}$ mortality.

\section{Received 13 March 2012; accepted 10 July 2012; published online 12 August 2012}

\section{References}

1. Langmann, B., Duncan, B., Textor, C., Trentmann, J. \& Van der Werf, G. R. Vegetation fire emissions and their impact on air pollution and climate. Atmos. Environ. 43, 107-116 (2009).

2. Field, R. D. \& Shen, S. S. P. Predictability of carbon emissions from biomass burning in Indonesia from 1997 to 2006. J. Geophys. Res. 113, G04024 (2008).

3. Jones, D. S. ASEAN and transboundary haze pollution in Southeast Asia. Asia Eur. J. 4, 431-446 (2006).

4. World Health Organization WHO Air Quality Guidelines for Particulate Matter, Ozone, Nitrogen Dioxide and Sulfur Dioxide (World Health Organization, 2006).

5. Tosca, M. G., Randerson, J. T., Zender, C. S., Flanner, M. G. \& Rasch, P. J. Do biomass burning aerosols intensify drought in Equatorial Asia during El Niño? Atmos. Chem. Phys. 10, 3515-3528 (2010)

6. Heil, A. \& Goldammer, J. G. Smoke-haze pollution: A review of the 1997 episode in Southeast Asia. Reg. Environ. Change 2, 24-37 (2001).

7. Baccini, A. et al. Estimated carbon dioxide emissions from tropical deforestation improved by carbon-density maps. Nature Clim. Change 2, 182-185 (2012).

8. Van der Werf, G. R. et al. Global fire emissions and the contribution of deforestation, savanna, forest, agricultural, and peat fires (1997-2009). Atmos. Chem. Phys. 10, 11707-11735 (2010).

9. Pechony, O. \& Shindell, D. T. Driving forces of global wildfires over the past millennium and the forthcoming century. Proc. Natl Acad. Sci. USA 107, 19167-19170 (2010).

10. Johnston, F. H. et al. Estimated global mortality attributable to smoke from landscape fires. Environ. Health Perspect. 120, 695-701 (2012).

11. Van Der Werf, G. R. et al. Climate regulation of fire emissions and deforestation in equatorial Asia. Proc. Natl. Acad. Sci. USA 105, 20350-20355 (2008).

12. Wooster, M. J., Perry, G. L. W. \& Zoumas, A. Fire, drought and El Niño relationships on Borneo (Southeast Asia)in the pre-MODIS era (1980-2000). Biogeosciences 9, 317-340 (2012).

13. Siegert, F., Ruecker, G., Hinrichs, A. \& Hoffmann, A. A. Increased damage from fires in logged forests during droughts caused by El Niño. Nature 414, 437-440 (2001).

14. Frankenberg, E., McKee, D. \& Thomas, D. Health consequences of forest fires in Indonesia. Demography 42, 109-129 (2005).

15. Emmanuel, S. C. Impact to lung health of haze from forest fires: The Singapore experience. Respirology 5, 175-182 (2000).

16. http://www.esrl.noaa.gov/psd/enso/mei/table.html.

17. Textor, C. et al. The effect of harmonized emissions on aerosol properties in global models-an AeroCom experiment. Atmos. Chem. Phys. 7, 4489-4501 (2007).

18. Naeher, L. P. et al. Woodsmoke health effects: A review. Inhal. Toxicol. 19, 67-106 (2007).

19. Naidoo, R., Malcolm, T. \& Tomasek, A. Economic benefits of standing forests in highland areas of Borneo: Quantification and policy impacts. Conserv. Lett. 2, 35-44 (2009).

20. Collins, M. et al. The impact of global warming on the tropical Pacific Ocean and El Niño. Nature Geosci. 3, 391-397 (2010).

21. Giglio, L. et al. Assessing variability and long-term trends in burned area by merging multiple satellite fire products. Biogeosciences 7 , $1171-1186$ (2010) 
22. Bey, I. et al. Global modeling of tropospheric chemistry with assimilated meteorology- Model description and evaluation. J. Geophys. Res. 106, 23073-23095 (2001).

23. Van Donkelaar, A. et al. Global estimates of ambient fine particulate matter concentrations from satellite-based aerosol optical depth: Development and application. Environ. Health Perspect. 118, 847-855 (2010).

24. United Nations World Population Prospects: The 2010 Revision CD-ROM edn (United Nations, 2011).

25. Pope, C. A. et al. Lung cancer and cardiovascular disease mortality associated with ambient air pollution and cigarette smoke: Shape of the exposure-response relationships. Environ. Health Perspect. 119, 1616-1621 (2011).

26. Ostro, B. Outdoor air Pollution: Assessing the Environmental Burden of Disease at National and Local Levels Vol. 5 (WHO Environmental Burden of Disease Series, World Health Organization, 2004).

27. World Health Organization Death Estimates for 2008 by Cause for WHO Member States (2011); available via http://go.nature.com/2pcb7c.

28. Center for International Earth Science Information Network (CIESIN) and Centro Internacional de Agricultura Tropical (CIAT) Gridded Population of the World Version 3 (GPWv3): Population Grids (SEDAC, 2005); available at http://sedac.ciesin.columbia.edu/gpw.

29. Center for International Earth Science Information Network (CIESIN), United Nations Food and Agriculture Programme (FAO) and Centro Internacional de Agricultura Tropical (CIAT). Gridded Population of the World: Future Estimates, 2015 (GPWv3): Population Grids (SEDAC, 2005); available at http://sedac.ciesin.columbia.edu/gpw.
30. Bell, M. L., Dominici, F. \& Samet, J. M. A meta-analysis of time-series studies of ozone and mortality with comparison to the national morbidity, mortality, and air pollution study. Epidemiology 16, 436-445 (2005).

\section{Acknowledgements}

We are grateful to P. Kasibhatla for his help with the GEOS-Chem model runs. We also thank the local staff at B. K. Tabang and T. Rata for the WDCGG $\mathrm{O}_{3}$ data, M. Brauer for the annual $\mathrm{PM}_{2.5}$ data and $\mathrm{K}$. Wolter at NOAA for the El Niño index. This work was supported by a National Sciences Foundation graduate research fellowship and NASA award NNX11AF96G. GFED3 is publicly available at http://www.globalfiredata.org.

\section{Author contributions}

R.S.D., A.V. and M.E.M. designed the study. G.F., A.V. and M.E.M. conducted the model runs; R.S.D., A.V., J.T.R., D.T.S., Y.C. and M.E.M. contributed to the model analysis; P.L.K. and M.E.M. conducted the health estimates. All authors contributed to the writing of the manuscript.

\section{Additional information}

Supplementary information is available in the online version of the paper. Reprints and permissions information is available online at www.nature.com/reprints. Correspondence and requests for materials should be addressed to M.E.M.

\section{Competing financial interests}

The authors declare no competing financial interests. 